\title{
Superior-subordinate Conflict Management Styles
}

\section{an Empirical Study of Malaysian Companies}

\author{
Kim Lian Lee \\ Faculty of Management \& Information Technology, University College Sedaya International \\ 3, Jalan Jenaris 2/1, Taman Jenaris 2, Kajang, Selangor, Malaysia \\ E-mail:kllee@ucsi.edu.my
}

\begin{abstract}
This study examined the relationships between organizational context, conflict handling styles and subordinates' satisfaction with supervision. Data from 139 respondents from major industries in Malaysia including service, manufacturing, mining and construction demonstrated that subordinates were more satisfied with their superiors' supervision through their exercise of integrating, compromising, and obliging styles. On the other hand, subordinates who perceived their superiors as primarily utilizing dominating and avoiding style viewed them as incompetent in supervision and thus lowering their level of satisfaction with supervision. Among the conflict handling styles, integrating was most correlated with organic structure. The organic structure was found to be positively correlated with the satisfaction with supervision. These results implied that organic structure can be a potent force in maintaining organizational stability, although not unambiguously, the present results also seemed to suggest that subordinates tend to be less satisfied with superiors with wider span of control.
\end{abstract}

Keywords: Organizational context, Structure, Span of control, Conflict management styles, Satisfaction with supervision, Organizational behavior, Managerial supervision

\section{Introduction}

Conflict is known to be inseparable in all human interactions. In any organization, role differentiation acquires different use of conflict handling styles. Work direction, reward, supervision, discipline and performance review also involve the use of conflict handling styles. Organizational change and control may be viewed from a conflict perspective. In attempts to explain the nature or dynamics of a particular organizational phenomenon, conflict may be incorporated as a causal factor.

A great question confronting our industrial society is concerned with the issue on how can the skills of managers be enriched so as to make it possible for them to act with greater proficiency when their contributions are from dealing with and through people especially their subordinates? One way of looking into this issue is from the conflict perspectives. The attention to interpersonal relationships is due to our belief that sound superior-subordinate relationships are important and consistent with humanistic and cooperative work environment sought by contemporary managers. It is also believed that positive interpersonal relationship at workplace is able to increase subordinates' satisfaction with supervision and subordinates with high levels of satisfaction are more likely to be committed to the organization (Brown \& Peterson, 1993).

Differences in the perception of conflict possess implication in its own right. This is due to superior's uses of conflict styles may be reinforced by subordinates' responses or the superior may anticipate subordinates' reaction to the use of conflict styles. It is worthwhile for the superior to be aware of the existence of multiple sources of conflict in work situations and how it promote subordinates' job satisfaction since dissatisfaction itself could lead to many organizational dysfunctions such as decline in work performances, absenteeism, high turnover, and job stress (Churchill, Ford \& Walker, 1976; Fisher \& Gittelson, 1983; Van Sell, Brief \& Schuler, 1981; Rahim \& Buntzman, 1989).

On the other hand, the importance of organizational contexts as variables for organizational studies have also been well established as correlates or consequences of conflict handling styles. Unfortunately, most of the research attention was in the context of job design or job characteristics. Less attention has been given in linking the types of conflict handling styles with organizational variables such as span of control and structure, and subordinates' satisfaction with supervision. Knowing how conflict handling styles related to organizational context and supervisory satisfaction will enable the superior to change or maintain his/her conflict styles to achieve desirable outcomes. Thus, this study which seeks to find out the correlates and consequences of conflict handling styles and subordinates' satisfaction with supervision would ultimately contribute to the knowledge of organizational behavior in this area. 


\subsection{Research Questions}

The delineation of research question is to find out the various methods of conflict handling styles employed by superior in the Malaysian companies, what are the correlates and consequences of conflict handling styles and how it affects subordinates' job satisfaction. Hence, this study seeks to answer the followings research questions.

(1) Are there any significant differences in subordinates' satisfaction with supervision when subjected to different conflict management styles?

(2) Are there any predictable relationships between organizational contextual variables and conflict handling styles and subordinates' satisfaction with supervision?

\subsection{Scope of the Study}

The foundation of this study rests upon the interaction among major variables as depicted in Figure 1. (Note 1) The primary data used in this study is secured through survey questionnaire. Cross-sectional data of respondents from Malaysian three industries namely, service, manufacturing, and mining and construction is subjected to quantitative analysis to test the conflict handling styles model.

\section{Literature Review}

This section reviews the relevant constructs and variables as well as their interactions involving: (1) Typologies of conflict handling styles; (2) Organizational contextual variables: Span of control and Structure; and finally (3) Supervision with satisfaction.

\subsection{Typologies of Conflict Handling Styles}

There are various styles of behavior by which interpersonal conflict can be handled. In order to manage conflict effectively, one style may be more suitable than the other depending upon the situation. Follett (1940) conceptualized five methods of handling conflict in organizations i.e. domination, compromise, integration, avoidance and suppression. Conflict management style has been continuously measured by a variety of different taxonomies. Researchers in social psychology and organizational behavior have proposed models that reduce the myriad tactics of conflict handling styles. One of the first conceptual schemes for categorizing conflict revolved around a simple cooperation-competition dichotomy followed the intuitive notion that styles can be arrayed on a single dimension ranging from competition or selfishness (Deutsch, 1949, 1973). However, doubts were raised over the ability of the dichotomy to reflect the complexity of an individual's perceptions of conflict behavior. In other words, the limitation of single-dimension model is that it fails to encompass styles that involve high concern for both self and other, and styles that involve neither high concern for neither self nor other (Ruble \& Thomas, 1976; Smith, 1987, Thomas \& Kilmann, 1974; Pruitt \& Rubin, 1986).

Subsequent theorists then drawn on a new two-dimensional grid for classifying the styles as suggested by Blake and Mouton $(1964,1970)$ which is a self-oriented and other-oriented concern. Other authors have labeled the two dimensions differently (e.g., Thomas \& Kilmann, 1974; Rahim, 1983a, 1986; Thomas, 1976; Pruitt \& Rubin, 1986; Van de Vliert \& Hordijk, 1989 , but the basic assumptions have remained similar. Although it has also been debated that individuals select among three or four conflict styles (Pruitt, 1983; Putnam \& Wilson, 1982), but evidence from confirmatory factor analyzes concluded that the five factor model has a better fit with data than models of two, three and four styles orientations (Rahim \& Magner, 1994, 1995). While the conflict styles somewhat differ in terms of name, the general principles and basic descriptions of the styles appear very similar (Kozan, 1997).

For the purpose of this study, the researcher has chosen Rahim and Bonoma (1979), and Rahim (1983, 1985, 1986a, 2001) styles of handling interpersonal conflict on two basic dimensions: concern for self and concern for others. It is among the most popular styles of handling conflict used in research. In fact, Rahim and Bonoma's (1979) model was based on Blake and Mouton's (1964) grid of managerial styles as well as the Thomas-Kilmann MODE instrument (1974). Specifically, Rahim and Bonoma confirmed and refined the factor structure of the managerial grid through contact over 1,200 corporate managers across the United States (Rahim, 1983). This work leads them to identify five specific conflict styles as shown in Figure 2. (Note 2) Rahim (1983, 1986a, 2001) defines styles of handling conflict as integrating, obliging, dominating, avoiding and compromising. It was Rahim's idea that “organizational participants must learn the five styles of handling conflict to deal with different conflict situations effective" (Rahim, 1986a, p.30).

\subsubsection{Integrating Style}

High concern for self and others reflects openness, exchange of information, and examination of differences to reach an effective solution acceptable to both parties. The integrating style concentrates on problem solving in a collaborative manner. Individuals with this style face conflict directly and try to find new and creative solutions to problems by focusing on their own needs as well as the needs of others. Lawrence and Lorsch (1967) found the problem-solving (integrating) style to be more effective than other styles for attaining integration of the activities of different subsystems. When the issues are complex, this style is suitable in utilizing the skills and information possessed by different parties to formulate solutions and successful implementations. Thus, the integrating style is believe to be both effective and appropriate in managing 
conflicts and, therefore, is perceived as highly competent (Tutzauer \& Roloff, 1988).

\subsubsection{Obliging Style}

Low concern for self and high concern for others style is associated with attempting to play down the differences and emphasizing commonalities to satisfy the concern of the other party. Obliging is associated with accommodating behaviors that include putting aside one's own needs to please the partner, passively accepting the decisions the partner makes, making yielding or conceding statements, denying or failing to express one's needs, and explicitly expressing harmony and cooperation in a conflict situation (Wilmot \& Hocker, 2005). These types of conflict strategies are indirect and cooperative (Blake \& Mouton, 1964). It can be used as a strategy when a party is willing to give up something with the hope of getting something in exchange from the other party when needed.

\subsubsection{Dominating Style}

High concern for self and low concern for others style has been identified with win-loses orientation. The dominating style relies on the use of position power, aggression, verbal dominance, and perseverance. This style is direct and uncooperative (Blake \& Mouton, 1964). Within interpersonal context, the dominating (competing/distributive) style has been found to be associated with low levels of effectiveness and appropriateness. However, Papa and Canary (1995) suggested that the dominating style might be somewhat effective in organizational contexts when there are production-related goals. In this case, an individual might use power strategies and aggression to effectively accomplish a goal, even though these strategies may be seen as inappropriate at a relational level.

\subsubsection{Avoiding Style}

Low concern for self and others style has been associated with withdrawal, buck-passing, or sidestepping situations. An avoiding person fails to satisfy his or her own concern as well as the concern of the other party. This style is useful when the issues are trivial or when the potential dysfunctional effect of confronting the other party outweighs the benefits of the resolution of conflict.

\subsubsection{Compromising Style}

Intermediate in concern for self and others style involves give-and-take whereby both parties give up something to make a mutually acceptable decision. It may mean splitting the difference, exchanging concessions, or seeking middle-ground position. It may be appropriate when the goals of the conflicting parties are mutually exclusive or when both parties, who are equally powerful, e.g. labor and management, have reached a deadlock in their negotiation. This style may be of some use in dealing with strategic issues, but heavy reliance on this style may be dysfunctional.

\subsection{Organizational Contextual Variables}

Several researches have attributed the conflict handling style to various factors e.g. span of control (Morris, Steers \& Roch, 1979) and organizational structure (Weber, 1946; Burns \& Stalker, 1961).

\subsubsection{Span of Control}

Span of control is the number of subordinates reporting to a superior. If the span is narrow, manager will have few underlings. Narrow span will provide closer supervision and tighter "boss-oriented" controls; thus resulting in tall, hierarchical structure. Small spans of control increase the time a superior can work alongside of any given subordinates, and therefore provide greater chances for building shared goals as well as coaching and feedback (Likert \& Likert 1976; Tannenbaum 1968). According to Taylor (1911) consistent with these arguments, Porter and Lawler (1964) found that superiors with small spans of control were more available for coaching and feedback.

If it is wide span of control, manager will have a larger number of subordinates reporting to them. As a consequence, the structure will be flatter (Jones, 1994). In general, wider span has lesser opportunity for supervision due to the large number of subordinates. Managers with larger spans were more likely to handle problems with subordinates in a more formalized, impersonal manner, using warnings and punishments instead of coaching and feedback (Kipnis \& Cosentino 1969; Kipnis \& Lane 1962; Goodstadt \& Kipnis, 1970; Ford 1981; Heller \& Yukl 1969). While wider span of control may reduce management costs, the effectiveness of manager may be compromised. In turn this could influence job satisfaction and turnover (Altaffer, 1998).

On the other hand, there seems to be several positive effects on individual attitudes and behavior when the span of control is large. Employee morale will improve with a broader span since subordinates will be subjected to a lesser degree of detailed supervision. In fact, one of the worst aspects of a narrow span of control is the opportunity it gives a manager to harass his subordinates. Wider spans will generally entail more responsibility be given to subordinates, thereby making the job more fulfilling. At the same time, a flatter structure will provide more growth for the subordinates and create more reliance and trust from the supervisor. Thus, span of control can be an important variable in the superior-subordinate exchange relation. Moreover, studies by Morris, Steers and Roch (1979) shows that superior span of control contributes to the explained variance in role conflict. Extending this argument, it is also presupposed that supervisory span will have influence to the way manager handling conflict. 


\subsubsection{Organizational Structure}

The study of organizational structure relies on the differentiation of position, formulation of rules and procedures, and prescriptions of authority. Wider focus in these formal dimensions of structure has been heavily influenced by Weber's (1946) work on bureaucracy, which depicted precise and impersonal structures of tasks, rules, and authority relations as central to rationalizing the real world. The extension and replication of Weber's work on structure are plentiful (Hall, 1996; Meyer, 1972; Pugh, Hickson, Hinings \& Turner, 1968). Various dimensions of structure serve as framework for the analysis of interactive patterns of organizational members which can relate to individual performance or satisfaction.

In this study, structure is conceptualized on a mechanistic-organic continuum. Burns and Stalker (1961) suggest that some successful organizations or work group tend to favour vertical specialization and control or horizontal specialization and coordination. When an organization stresses rules, policies, and procedures, this will be leading to rigidity and inflexibility and when organizations specifies the techniques for decision-making, and develops an elaborate control system backed by a centralized staff, this is called "mechanistic" or "bureaucratic". This type of organization tends to have a vertical emphasis as the staff units will always be placed at the top of the system. In mechanistic or bureaucratic organizations, employee alienation and strict adherence to roles often mean avoiding conflict by resorting to intransigence.

Burns and Stalker (1961) called the opposite type "organics". This strategy tends to emphasize horizontal specialization and coordination and there are comparatively few rules enforced in the organization. The benefit of the organic structure is its flexibility, adaptability, and early recognition of external change (Burn \& Stalker, 1961; Lawrence \& Lorsch, 1967; Webb \& Dawson, 1991).

Both of these structures provide consistent patterns of organizing that can be adjusted to fit pressures from contextual variables. Obviously each of the two "ideal" patterns appears to have its own strengths and weaknesses. The mechanistic pattern appears more suited when organizations are most interested in efficiency (Litterer, 1973). Conversely, where there is high variability, and an organization is less sure of how to transform inputs to outputs, the organic form may be preferred (Reimann \& Negandhi, 1975).

\subsection{Satisfaction with Supervision}

Satisfaction with supervision has received extensive attention in organizational research. In this study, satisfaction is defined as, "a pleasurable or positive emotional state resulting from the appraisal of one's job" (Locke, 1976). Work satisfaction is an important workplace construct and one that is of concern for effective management. Thus, numerous research findings suggest that conflict management style is related to various aspects of employee satisfaction are of interest and represent an important extension to the job satisfaction literature. These findings imply that satisfaction with supervision is one of the most important attitudinal issues in the workplace that managers face (Babin \& Boles, 1996). Smith, Kendall, and Hulin (1969), in their well documented measure, the Cornell JDI (Cornell Job Descriptive Index) described five areas of satisfaction: the work itself, the supervision, the co-workers, the pay, and the opportunities for promotion on the job. Since the theme of the present study is on the superior-subordinate relationships, the job-facet satisfaction is most relevant to satisfaction with supervision. The conflict handling styles which superior uses in an organization in supervising their subordinates can have a broad impact on the subordinates' attitude towards work. The amount of supervision and direction given to the subordinates will increase their satisfaction with supervision. Conversely, many studies recorded that supervision to the extent that the superior exercises dominating and avoiding is found to have a negative impact on the subordinates' satisfaction (Kahn, Wolfe, Quinn, Snoeck, \& Rosenthal, 1964).

\section{Hypothesized Relationships}

The hypotheses were grouped into several sets. There are: (1) those dealing with consequences of conflict handling styles upon subordinates' satisfaction with supervision (H1a \& H1b), (2) those dealing with association of organizational context upon conflict handling styles ( $\mathrm{H} 2 \mathrm{a} \& \mathrm{H} 2 \mathrm{~b})$, and (3) those dealing with the association of organizational context and satisfaction with supervision (H3a). More specifically, the following hypotheses were formulated which serve as focal points for the study.

Organizational conflict researchers (e.g. Rahim \& Buntzman, 1989; Burke, 1970; Lawrence \& Lorsch, 1967; Likert \& Likert, 1976) generally assert that superior who exhibits integrating, compromising, and obliging styles are more prong to foster a cordial dyadic relationships among superiors and subordinates. These styles are related to an effective conflict management. Several studies on the integrating, compromising, and obliging styles of handling conflict show consistent results in satisfaction with supervision (Korabik, Baril, \& Watson, 1993; Tutzauer \& Roloff, 1988; Wall \& Galanes, 1986; Vigil-King, 2000). Likewise, other studies recorded that superior uses dominating and avoiding is linked to negative effect on subordinates' satisfaction (Kahn, Wolfe, Quinn, Snoeck, \& Rosenthal, 1964). Thus, it can be hypothesized that:

Hypothesis H1a: Superior's integrating, obliging, and compromising styles have direct and positive effect on the subordinates' satisfaction with supervision.

Hypothesis H1b: Superior's dominating, and avoiding styles have negative effect on the subordinates' satisfaction with supervision. 
Superiors who possess wider span of control are more likely to deal conflict with subordinates in a more formalized, impersonal manner, using warnings and punishments (Kipnis \& Cosentino 1969; Kipnis \& Lane 1962). In addition, as spans of control increase, managers are found to more autocratic (Heller \& Yukl, 1969). Likewise, Burns and Stalker (1961) define organic structure as horizontal specialization and there are few rules being emphasized in the organization. Work group employing organic structure is having less conflict and the superior tends to use more compromising or integrating style. As such, the following hypotheses are predicted:

Hypothesis H2a: Wider span of control is positively associated with dominating, and avoiding style, but negatively associated with integrating, obliging and compromising style.

Hypothesis H2b: Organic structure is negatively associated with dominating and avoiding style.

In relation to organizational context, research by Meadow (1980) concluded that organic structure is positively related to satisfaction of higher order needs, but mechanistic structure is associated with their frustration. This statement is also supported by Rahman, Mawdudur, Zanzi and Alberto (1995) in their study which confirms organic structure is associated with greater job satisfaction with supervision. Considering these past findings, the following hypotheses are suggested as follows:

Hypothesis H3a: Organic structure has direct and positive effect on the satisfaction with supervision.

\section{Research Methodology}

\subsection{Sampling Design}

The sample for this study comprises of the executives, managers and professionals in services, manufacturing, mining and construction companies. This sample was selected for three reasons: (1) measurement of perceptions on constructs such as conflict handling styles, structure and span of control requires some abstract and purposeful thinking which is certainly helped by having a certain stature in the organization, (2) this represents the group of more educated people who are more aware of the kind of conflict styles with superiors and normally hinge more on the non-traditional organizational-based kind of relationship to sustain their interest in the organization, and (3) the industries are among the more dominant industries in Malaysia that contribute significantly to the Gross Domestic Product and labour employment. The companies that met the above criteria were selected from the list of companies gathered from the Federation of Manufacturers Malaysia (FMM), Construction Industry Development Board (CIDB), and Malaysian Trade and Commerce Directory. Random sampling was used in selecting the samples from the large database. Data from subjects was obtained through survey questionnaire.

\subsection{Research Instruments}

All data used in the study consist of responses to questionnaire items. Measures of the relevant constructs were taken from previous studies and are discussed here.

\subsubsection{Conflict Handling Style}

Conflict management styles were measure by using the Form C of ROCI-II (Rahim, 1983a). This multi-item instrument contains 28 items uses a 5-point Likert scale to assess subordinates' perceptions on supervisor's style of handling conflict. The ROCI-II was designed to measure 5 dimensions or styles of resolving conflict. 7 items for measuring integrating style, 6 items each for measuring obligating style and avoiding styles, 4 items for measuring compromising style and 5 items for measuring dominating style.

\subsubsection{Organization Structure}

Structure is conceptualized on a mechanistic-organic continuum using Burns and Stalker scale (1961). Organization structure was represented a 7 item scale which measures organicity, i.e. the extent to which organizations are structured as organic versus mechanistic entities. This scale was also developed by Khandwalla (1977a, 1977b) and later used by Covin and Slevin (1989) and Low (2005).

\subsubsection{Span of Control}

Span of control is a measure of the total number of person being supervised by a superior. For statistical analysis the span of control is measured as the natural logarithm of this number.

\subsubsection{Satisfaction with Supervision}

The instrument used to measure satisfaction with supervision is the updated version of the original Job Descriptive Index (JDI; Smith at el., 1969) which was later revised by Roznowski (1989). The instrument is made up of 18 items.

\subsection{Data Analysis Techniques}

Simple correlation was used to measure the relationships among conflict handling styles and subordinates' satisfaction with supervision. It allowed a straight forward interpretation of the hypothesized relationships. 


\section{Research Results and Discussions}

\subsection{Sample Characteristics}

From the total of 145 responses received, data from 139 respondents were usable. By ethnic group, $42 \%$ of the respondents were Chinese, $38 \%$ were Malay, and $17 \%$ were Indian, while other races made up the rest. By gender, 53\% were male and $47 \%$ were female. In terms of age, the highest proportion of respondents fell into the 23-30 years age group. They accounted for $63 \%$ of the total number of respondents. This was followed by the $31-40$ years age group (33\%), while those above 41 years old accounted for the remaining.

On the whole, the education level of the respondents was high. Nearly $84 \%$ of the respondents had education up to tertiary level. Only $1 \%$ of the respondents had no tertiary education. The high educational level was reflected in the position or the type of occupation held by the majority of the respondents i.e. 7 Directors/General Managers/ Assistant General Manager, 3 Senior Managers, 46 Departmental Manager/Assistant Managers and 83 Executives.

The average salary of the respondents was higher than the population's average. The survey data showed that $27 \%$ of the respondents earned more than RM5000 per month, 14\% earned RM4001 to RM5000 per month, 49\% earned RM3001 to RM4000 per month, and 10\% earned RM2001 to RM3000 per month.

On average, the respondents had worked in the present company for 4 years with a standard deviation of 3.6 years. It was noted that $59 \%$ of the total respondents had worked for 1 to 3 years in the present company, $25 \%$ had worked between 4 to 6 years, $12 \%$ had worked between 7 to 9 years, and $4 \%$ had worked between 10 and 13 years, while only $1 \%$ of the respondents had worked longer than 20 years in the present company. The degree of job mobility among respondents was reflected in the average number of previous jobs held by respondents i.e. 2 jobs. For the present sample, 20\% responded that they had no previous job, $29 \%$ had one, 32\% had two, 11\% had three and the rest reported that they had more than 4 previous jobs.

In terms of the organizational size, the survey had selected sample which represents the medium to large sized Malaysian companies. It was found that $39 \%$ of the companies had 1 to 100 employees, $7 \%$ had 101 to 200 employees, $9 \%$ had 201 to 400 employees, $17 \%$ had 401 to 1000 employees and 29\% had more than 1000 employees. Classifying the business according to the type of industry revealed that a greater portion of the companies are in services industries (55\%), followed by manufacturing industries $(23 \%)$ and $6 \%$ of mining and construction.

The survey revealed the following information about the respondent's superior. A 76\% superiors reported in the survey were males and $24 \%$ were female. A majority of them were holding medium to high management positions. Racial composition of the superiors was: $46 \%$ Chinese, $41 \%$ Malay, $8 \%$ Indian and 5\% from other races. On average, the superiors had worked in the organization for 11 years with a standard deviation of 7.6 years - longer than the subordinates' average. Only $1 \%$ had worked for less than a year, 30\% had worked between 1 and 5 years, 29\% had worked between 6 and 10 years, $17 \%$ had worked between 11 to 15 years, $13 \%$ had worked between 16 to 20 years and $10 \%$ had worked more than 20 years in the present company. The superiors were holding various positions in the company with $33 \%$ of them in the first hierarchical level, $30 \%$ in the second level, and $26 \%$ in the third level, while only a fraction of them were in the lower management positions. Their educational level was also predictably high, with $55 \%$ of them having had tertiary education. Only $6 \%$ had up to either primary or secondary education. By designation, 64 of the superiors were the directors/general manager/ assistant general manager of companies, 23 were the senior managers, 50 were the departmental manager/assistant managers and the rest consisted of executives.

\subsection{Validating the Scales}

The standardized Cronbach Alpha for each subscale is provided in Table 1. (Note 3)

\subsection{Testing of Hypotheses}

Hypothesis H1a states that superior's integrating, compromising and obliging styles have direct and positive effect on the subordinates' satisfaction with supervision. The correlational analysis in Table 2 (Note 4) provided good support for H1a. The integrating, compromising and obliging styles of handling conflict showed positive relationships and highly correlated with satisfaction with supervision. These three correlations were significant beyond .01 level.

In the relationship of conflict handling styles to satisfaction with supervision, integrating style ranked highest among other style exercises $(\mathrm{r}=.62, \mathrm{p}<.01)$. This was followed by compromising style and obliging style which had coefficients of correlation of $.33, \mathrm{p}<.01$ and $.29, \mathrm{p}<.01$ respectively. The ranking of intercorrelation was somewhat similar to the study of Rahim and Buntzman (1989) conducted on respondents with post graduate working experience. It was expected that integrating, compromising and obliging style represents a high level of inner acceptance between superior and subordinate relationships. As Rahim and Buntzman (1989) found out, the integrating, compromising, and obliging style of handling conflict tends to foster a more satisfied, cooperative and prolonged relationships among superiors and subordinates.

Literature on organizational conflict also shows that integrating, compromising, and obliging styles are positively associated with supervision with satisfaction. Burke (1970) suggested that, in general, a confrontation (integrating), compromising, 
and obliging styles were related to the effective management of conflict that lead to supervisory satisfaction, while forcing (dominating) and withdrawing (avoiding) were related to the ineffective management of conflict that lead to supervisory dissatisfaction. Lawrence and Lorsch (1967) indicated that an integrating, compromising, and obliging styles dealing with inter-group conflict was used to a significantly greater degree in higher performing organizations than lower performing organizations.

A field study with a convenience collegiate sample by Rahim and Buntzman (1989) suggested that the integrating (problem solving), compromising and obliging styles of handling conflict is positively correlated with supervision with satisfaction. Likert and Likert (1976) strongly argued and provided some evidence to suggest that an organization that encourages participation and problem solving (integrating) behaviors attains a higher level of satisfaction with supervision. Several studies on the integrating, compromising, and obliging styles of handling conflict show consistent results. These styles result in high joint benefit for the parties, better decisions, and greater satisfaction with supervision (Korabik, Baril, \& Watson, 1993; Tutzauer \& Roloff, 1988; Wall \& Galanes, 1986). Vigil-King (2000) study shows that superior that use more integrating conflict management styles are likely to have higher subordinates' supervision with satisfaction than superior using less integrating styles.

Among subordinates, integrative style emerges as a very important cue for acceptance and recognition of the superior's conflict management style as reflected in the present result. It most likely gains their compliance and least likely to provoke their resistance (Gross \& Guerrero, 2000). Similarly, greater satisfaction with supervision among subordinates may lead to greater cooperation and heightened dependence. In the superior-subordinate interaction, subordinates frequently say what is acceptable rather than what they know is true. Therefore, an individual subordinate may use a more obliging style with superiors. This is due to subordinates are likely to withdraw from a conflict situation (Kahn, Wolfe, Quinn, Snoek \& Rosenthal, 1964).

As the present results supported the general view the integrating, compromising and obliging style has a positive effect on the superior-subordinate relationship. The high degree of intercorrelations among the integrating, compromising and obliging served to temper the previous discussions and tended to suggest that while integrating style emerged as the dominant explanatory of conflict handling style, its effective utilization might be tied to some extend, to the superior's exercise of a combination of other style such as compromising and obliging style.

Hypothesis H1b predicts that superior's dominating and avoiding styles have negative effect on subordinates' satisfaction with supervision. Both the dominating and avoiding styles showed relatively negative but significant correlation $(\mathrm{r}=-.50$, $\mathrm{p}<.01 ; \mathrm{r}=-.24, \mathrm{p}<.01$ respectively) with supervisory satisfaction. In the dominating style, subordinates' responses tend to be dependent on the normative acceptance of the position and prerogatives of the organization at large including its leadership. The present result concurred with the conclusion made by Rahim (1986) and Burke (1970) that dominating and avoiding styles are less effective means of supervisory satisfaction.

The present result seems to support Hypothesis H1b. The study indicated that the dominating style perceived held by a superior was negatively associated with supervisory satisfaction. Past researchers supported this correlation (e.g. Van de Vliert, Euwema, \& Huismans, 1995; Van de Vliert, 1997; Rahim \& Buntzman, 1989; Gross \& Guerrero, 2000) have stated that dominating style which is derived from control over negative or punishing outcomes for others does not appear to be a suitable style for dealing with subordinates. It is negatively related with concern for the other party which will usually not improve the relationship (Sorenson, Morse \& Savage, 1999). The traditionalists believed that dominating is ineffective and can lead to conflict of social interaction. Although it has been found in some studies that individuals can achieve substantive outcomes through forcing behavior (De Dreu \& Van de Vliert, 1997; Rahim, 1992; Thomas, 1992) but people could not be forced into a deep-seated acceptance of organizational requirements.

Hypothesis H2a suggests that wider span of control is positively associated with dominating, and avoiding style but negatively associated with integrating, obliging and compromising style. The relationships as appeared in Table 2 (Note 4) between the perceptions of supervisory span of control and perceived conflict styles were not significant, although there were some marginal relationships, but logical with all the conflict styles. The interpretation of these results and their relevance to the hypothesis proposed in this study seems to vaguely suggest that wider span of control is positively associated with dominating $(\mathrm{r}=.11)$, follow by compromising $(\mathrm{r}=.05)$ style of handling conflict. The variable is negatively associated with integrating and $(\mathrm{r}=-.13)$ and avoiding $(\mathrm{r}=-.07)$ style of handling conflict. The results of the data analysis seemed to offer ideas on the direction of relationships, but yet failed to reach the desired statistical significance. Although Hypothesis H2a was not supported in statistical terms, some explanation may be offered with regards to the present results. As span of control is related to the number of subordinates reporting to their superior, wider the span of control is positively associated with dominating and avoiding style as superiors need to exercise dominating style to control their subordinates.

The present result seems to imply that superiors who were perceived to have broader span of control tend to exercise greater dominating style. The reason for this was not conclusive. Many plausible explanations were possible, but it was believed that superiors with wider spans were more likely to handle problems with subordinates in a more formalized, impersonal manner, using warnings and punishments instead of coaching and feedback (Kipnis \& Cosentino, 1969; Kipnis \& Lane, 
1962). Hence subordinates' attempts to exercise greater influence may be seen as a threat to the superior's control of their underlings. Furthermore, as the gap between superiors and subordinates will even likely to increase as a direct consequence of punitive procedures, the subordinates tend to avoid participation.

Weak relationship between integrating and broader span of control suggested that those who exercise integrating style over wider span of control accorded lesser control over subordinates. Though the degree of control by exercising of integrating style has been questioned, the very least the integrating style can foster better relationship for the subordinates to perform better. This conclusion was drawn from the assumption that people generally prefer integrating than dominating style and integrating approach can provide greater satisfaction with supervision. No comparison was made as there was no past research done with regard to this correlation.

It was interesting to note that there is some evidence that a manager's satisfaction increases as the number of subordinates supervised increases (Cummings \& Berger, 1976) but it might not indicate subordinates' satisfaction with supervision. This finding plays down the importance of span of control in contributing to the satisfaction with supervision and lead one think that span of control may not be as important as the perception of conflict handling style in ensuring subordinates' satisfaction.

Overall, the results agreed with hypothesis $\mathrm{H} 2 \mathrm{a}$. However, the present result should be used with caution as the measurement of both construct was not based on the objective measurement but on individual perceptions. Individual differences such as desire for position power, inner motivation, etc might intervene in the relationship between span of control and conflict handling style.

Hypothesis $\mathrm{H} 2 \mathrm{~b}$ states that organic structure is negatively associated with dominating and avoiding style. The relationship between organic structure and conflict handling styles was significant as one would expect. The result agreed with Hypothesis $\mathrm{H} 2 \mathrm{~b}$ that organic structure is negatively associated with avoiding $(r=-.23, \mathrm{p}<.01)$ and dominating style $(r=-.30$, $\mathrm{p}<$. $01)$. This was probably due to the reason that structure and conflict styles were very much a related concept. The former measures the organizational structural design while the latter measures one's style of handling conflict. Nonetheless, an important common element appeared to exist between them that explained their negative and statistically significant relationship between organic structure and both the dominating and avoiding style.

Hypothesis H3a suggests that organic structure has direct and positive effect on the satisfaction with supervision. Correlational result in Table 2 (Note 4) showed that organic structure was positively associated with the satisfaction with supervision $(\mathrm{r}=.19, \mathrm{p}<.05)$. A study was conducted by Meadow (1980) on Organic Structure, Satisfaction, and Personality found out that organic structure in small work groups is positively associated with the satisfaction of higher order needs. It was observed that strong personality aspiring towards dominance, autonomy, and achievement respond more positively to organic structure and more negatively to mechanistic structure. This statement also supported by Rahman, Mawdudur, Zanzi, Alberto (1995) as reported in their study that more organic structure and greater job satisfaction with supervision.

\section{Conclusion}

Overall, the results of this study were quite consistent with the hypotheses based upon other organizational studies involving qualified and professional people. The research instruments used in this study were tested and found to be reliable in our Malaysian work environment. The results provided some tentative, but hopefully useful guidance for organizational administration.

Inter correlations among the five styles of conflict handling showed that the results are closely similar to Rahim and Buntzman (1989). The results revealed that integrating, compromising and to some degree obliging are found to be in association with each other. These intercorrelations may give rise to a favorable halo effect with respect to the perceived influence, for example if a superior is perceived as having integrating style, this will also augment other styles (e.g. compromising, obliging) at his/her disposal. On the other hand, dominating was the least correlated with all other styles and most often stands alone. Among all the conflict styles, dominating was most related to avoiding style. It indicates that dominating and avoiding style tend to be used interchangeably. Though not considered as a serious disadvantage, notable intercorrelations among the five styles of handling conflict denote the difficulty of finding conflict style typology which is both exhaustive and conceptually distinct.

The conflict management styles were also found to be associated to an individual perception's of the source of conflict style. Superior who was perceived to exercise dominating style tends to exercise greater management control - giving little opportunity for the subordinate to be personally responsible for a meaningful portion of his/her works. In assessing the effectiveness of the various influence means, the results suggested that integrating, compromising and obliging should be emphasized to ensure subordinates' satisfaction with supervision. Dominating style should be minimized in any influence attempt except in situations that call for such approach, such as time of crisis or low performance. Comparative studies revealed an interesting difference in the rank ordering of superior styles of handling conflict. Study by Rahim and Buntzman (1989) ranked integrating, compromising and obliging as the most favorable, and dominating and avoiding as the lowest among conflict styles in eliciting subordinates' acceptance of supervision satisfaction. The results suggested a notion that the effectiveness of conflict handling style does relate to the situation and context of the job environment. Although the 
desirability of some conflict styles were obvious, it should be noted that they might not necessarily have same impact on all attitudinal and behavioral outcomes measures. For example, Rahim (1986), Bachman, Bowers and Marcus (1968) and Rahim and Buntzman (1989) discovered that integrating and compromising were more associated with organizational effectiveness, dominating style was the most important for complying with superior's request and integrating, compromising and obliging were most related to supervisory satisfaction.

The challenge of the contemporary organization is also to encourage the use of the integrating/problem solving style of handling conflict among superior and subordinates. Employees should also be trained not to engage in win-lose or bargaining style of handling conflict. This can be done by strengthening the integrating conflict-management style and discouraging the use of an avoiding style. To attain this goal, training in conflict management of subordinates and superiors and appropriate changes in organization design and culture would be needed (Rahim, 2001).

Among the conflict handling styles, integrating was found to be the most associated with organic structure. The organic structure appeared to be positively correlated with the satisfaction with supervision. These results implied that organic structure can be a potent force in sustaining organizational stability.

The extent of span of control a superior has is dependent on how many subordinates he/she supervises. The results indicate that there was some marginal relationship between supervisory span of control and conflict styles although there were not so significant. Therefore, it was concluded that there was a weak but positive correlation between span of control and dominating style. This was due to the fact that superiors with wider spans of control tend to practice more formal way when dealing with their subordinates. On the other hand, superior who adopts integrating style over wider span of control would consequently exert lesser control over subordinates although integrating style is said to be able to foster closer relationship between superior and subordinates. The results also showed that that subordinates tend to be less satisfied with superiors with wider span of control.

\section{References}

Altaffer, A. (1998). First-line managers: Measuring their span of control. Nursing Management, 29(7), 36.

Babin, B.J., \& Boles, J.S. (1996). The effects of perceived co-worker involvement and supervisor support on service provider role stress, performance and job satisfaction. Journal of Retailing, 72(1), 57-75.

Bachman, J.G., Bowers, D.G., \& Marcus, P.M. (1968). Bases of supervisory power: A comparative study in five organizational settings. In A.S. Tannenbaum (Ed.), Control in Organizations. New York: McGraw-Hill. pp. $229-238$.

Blake, R.R., \& Mouton, J.S. (1964). The managerial grid. Houston, Texas: Gulf Publishing Co.

Blake, R.R., \& Mouton, J.S. (1970). The fifth achievement. Journal of Applied Behavioral Science, 6, 413-426.

Brown, S.P., \& Peterson, R.A. (1993). Antecedents and consequences of salesperson job satisfaction: Meta-analysis and assessment of causal effects. Journal of Marketing Research, 30, 63-77.

Burns, T., \& Stalker, G.M. (1961). The management of innovation. London: Tavistock.

Burke, R.J. (1970). Method of resolving superior-subordinate conflict: The constructive use of subordinate differences and disagreements. Organizational Behavior and Human Performance, 5, 393-411.

Canary, D.J., \& Spitzberg, B.G. (1987). Appropriateness and effectiveness perceptions of conflict strategies. Human Communication Research, 14: 93-118.

Churchill, G.A., Ford, N.M., Jr., \& Walker, O.C., Jr. (1976). Organizational climate and job satisfaction in the sales force. Journal of Marketing Research, 13, 323-332.

Covin, J.G., \& Slevin, D.P. (1989). Strategic management of small firms in hostile and benign environments. Strategic Management Journal. 10, 75-87.

Cummings, L.L., \& Berger, C.J. (1976). Organizational dynamics. New York: 5(2), 34.

De Dreu C.K.W., \& Van de Vliert, E. (1997). Using conflict in organizations. London: Sage.

Deutsch, M. (1949). A theory of cooperation and competition. Human Relations, 2, 129-151.

Deutsch, M. (1973). The resolution of conflict: Constructive and destructive processes. New Haven and London, Yale University Press.

Fisher, C.D., \& Gittelson, R. (1983). A meta-analysis of the correlates of role conflict and ambiguity. Journal of Applied Psychology, 68, 320-333.

Follett, M.P. (1940). Constructive conflict. In H.C. Metcalf \& L. Urwick (Eds.), Dynamic Administration: The collected papers of Mary Parker Follet. New York: Harper. pp. 1-20.

Ford, J.D. (1981). Department context and formal structure as constraints on leader behaviour. Academic Management Journal, 24, 274-288. 
Goodstadt, B.E., \& Kipnis, D. (1970). Situational influences on the use of power. Journal of Applied Psychology. 54, 201207.

Gross, M.A., \& Guerrero, L.K. (2000). Managing conflict appropriately and effectively: An application of the competence model to Rahim's organizational conflict styles. International Journal of Conflict Management, 11, 200-226.

Hall, J. (1969). Conflict management survey: A survey on one's characteristics reactions to and handling of conflicts between himself and others. Conroe, TX: Teleometrics.

Hall, R.H. (1996). Organizations: structures, processes and outcomes. Englewood Cliffs, N.J.: Prentice Hall.

Heller, F. \& Yukl, G. (1969). Participation, managerial decision-making and situational variables. Organization Behaviour and Human Performance, 4, 227-241.

Jones, G. (1994). Organizational theory. Reading, MA, Addison-Wesley Publishing Co.

Kahn, R.L., Wolfe, D.M., Quinn, R.P., Snoek, J.D., \& Rosenthal, R.A. (1964). Organizational stress. Studies in role conflict and ambiguity. New York: Wiley.

Kipnis, D. \& Cosentino, J. (1969). Use of leadership powers in industry. Journal of Applied Psychology. 53, $460-466$.

Kipnis, D. \& Lane, W.P. (1962). Self confidence and leadership. Journal of Applied Psychology. 46, 291-295.

Khandwalla, P.N. (1977a). The design of organizations. New York: Harcourt-Brace-Jovanovich.

Khandwalla, P.N. (1977b). Some top management styles, their context and performance. Organization and Administrative Sciences, 7(4), 21-51.

Korabik, K., Baril, G.L., \& Watson, C. (1993). Managers' conflict management style and leadership effectiveness: The moderating effects of gender. Sex Roles, 29, 405-420.

Kozan, M.K. (1997). Culture and conflict management: A theoretical framework. International Journal of Conflict Management, 8(4), 338-360.

Lawrence, P.R., \& Lorsch, J.W. (1967). Organization and environment. Homewood, III: Irwin-Dorse

Lee, K.L. (2006). Superior's characteristics, organizational context, conflict handling styles and satisfaction with supervision. Unpublished MBA Thesis, University Malaya.

Likert, R. \& Likert, J.G. (1976). New ways of managing conflict. New York: McGraw-Hill.

Litterer, J. (1973). The analysis of organizations. New York: Wiley.

Locke, E.A. (1976). The nature and causes of job satisfaction. In Handbook of Industrial and Organizational Psychology. Marvin Dunnette. Chicago, IL. pp. 1297-1350.

Low, G.T. (2005). Strategic persistence and reorientation of the firms following an environmental shift: An empirical study of Malaysian manufacturing companies, Unpublished PhD Thesis, University Malaya.

Meadow, I.S.G. (1980). Organic structure, satisfaction and personality. Human Relations, 33(6), 383-392.

Meyer, M.W. (1972). Size and the structure of organizations: Formal structure as myth and ceremony. American Sociological Review, 37, 434-441.

Nunnally, J.C. (1978). Psychometric theory ( $2^{\text {nd }}$ Ed.) New York: McGraw-Hill.

Papa, M.J., \& Canary, D.J. (1995). Conflict in organizations: a competence-based approach. In A.M. Nicotera (Eds.), Conflict and Organizations: Communicative Processes. University of New York Press, Albany, NY. pp. 153-179.

Porter, L. \& Lawler, E. (1964). The effects of "Tall" versus "Flat" organization structure on managerial job satisfaction. Personnel Psychology, 17(2), 135-148.

Pruitt, D.G. (1983). Strategic choice in negotiation. American Behavioral Scientist, 27, 167-194.

Pruitt, D.G. \& Rubin, J.Z. (1986). Social conflict: Escalation, stalemate, settlement. New York: Random House.

Pugh, D.S., Hickson, D.J., Hinings, C.R., \& Turner, C. (1968). Dimensions of organizational structure. Administrative Science Quarterly, 13, 65-106.

Putnam, L.L. \& Wilson, C.E. (1982). Communicative strategies in organizational conflicts: Reliability and validity of a measurement scale. In M. Burgoon (Ed.), Communication Yearbook. pp. 629-652.

Rahim, M.A. (1983a). A measure of styles of handling interpersonal conflict. Academy of Management Journal, 26, 368-376

Rahim, M.A. (1983b). Rahim organizational conflict inventory-II, Form A. Palo Alto, CA: Consulting Psychologists Press.

Rahim, M.A. (1983c). Rahim organizational conflict inventory -I. Palo Alto, CA: Consulting Psychology Press.

Rahim, M.A. (1983d). Rahim organizational conflict inventory -II, Form A, B, \& C. Palo Alto, CA: Consulting Psychology 
Press.

Rahim, M.A. (1983e). Rahim organizational conflict inventories: Professional manual. Palo Alto, CA: Consulting Psychology Press.

Rahim, M.A. (1985). A strategy for managing conflict in complex organizations. Human Relations, 81-89.

Rahim, M.A. (1986). Referent role and styles of handling interpersonal conflict. Journal of Social Psychology, 126, 79-86.

Rahim, M.A. (1986a). Managing conflict in organization. New York: Praeger.

Rahim, M.A. (1986b). Referent role and styles of handling conflict: A model for diagnosis and intervention. Psychological Reports, 44, 1323-1344.

Rahim, M.A. (1992). Managing conflict in organizations ( $2^{\text {nd }}$ Ed.). New York: Praeger.

Rahim, M.A. (2001). Managing organizational conflict. Challenges for organization development and change. In R.T. Golembiewski (Ed.), Handbook of Organizational Behavior. New York: Marcel Dekker. pp. 365-387.

Rahim, M.A. \& Bonoma, T.V (1979). Managing organizational conflict: A model for diagnosis and intervention. Psychological Reports, 44, 1323-1344.

Rahim, M.A. \& Buntzman, G.F. (1989). Supervisory power bases, styles of handling conflict with subordinates, and subordinate compliance and satisfaction. Journal of Psychology, 123, 195-210.

Rahim, M.A. \& Magner, N.R. (1994). Convergent and discriminant validity of the Rahim organizational conflict inventory-II, Psychological Reports, 74, 35-38.

Rahim, M.A. \& Magner, N.R. (1995). Confirmatory factor analysis of the styles of handling interpersonal conflict: First-order factor model and its invariance across groups. Journal of Applied Psychology, 80, 122-132.

Rahman, Mawdudur, Zanzi, Alberta. (1995). A comparison of organizational structure, job stress, and satisfaction in audit and management advisory services in CPA firms. Journal of Managerial Issues, 7(3), 290.

Reimann, B. \& Negandhi, A. (1975). Strategies of administrative control and organizational effectiveness. Human Relations, $28,475-486$.

Roznowski, M. (1989). Examination of the measurement properties of the job descriptive index with experimental items. Journal of Applied Psychology, 74(5), 805-814.

Ruble, T.L. \& Thomas, K.W. (1976). Support for a two-dimensional model of conflict behavior. Organizational Behavior and Human Performance, 16, 143-155.

Smith, W.P. (1987). Conflict and negotiation: Trends and emerging issues. Journal of Applied Social Psychology, 17, 641677.

Smith, P.C., Kendall L.M. \&. Hulan C.L. (1969). The measurement of satisfaction in work and retirement. A strategy for the study of attitudes. Chicago: Rand McNally.

Sorenson, R.L., Morse, E.A. \& Savage, G.T. (1999). A test of the motivations underlying choice of conflict strategies in the dual-concern model. International Journal of Conflict Management, 10(1), 25-44.

Tannenbaum, A. (1968). Control in organizations. McGraw-Hill, New York.

Taylor, F.W. (1911). The principles of scientific management. Dover Publications. Toronto, Canada.

Thomas, K.W. (1976). Conflict and conflict management. In M.D. Dunnette (Ed.), Handbook of Industrial and Organizational Psychology. Chicago: Rand McNally. pp. 889-935.

Thomas, K.W. (1992). Conflict and negotiation processes in Organizations. In M.D. Dunnette and L.M. Hough (Eds.). Handbook of Industrial and Organizational Psychology. Palo Alto, CA: Consulting Psychologists Press. ${ }^{\text {nd }}$ Ed., pp. 651717.

Thomas, K.W. \& Kilmann, R.H. (1974). The Thomas-Kilmann conflict MODE instrument. Tuxedo, NY: Xicom.

Tutzauer, F. \& Roloff, M.E. (1988). Communication processes leading to integrative agreements: There paths to joint benefits. Communication Research, 15, 360-380.

Van de Vliert, E. (1997). Complex interpersonal conflict behavior: Theoretical frontiers, Hove, UK: Psychology Press.

Van de Vliert, E. \& Hordijk, J.W. (1989). A theoretical position of compromising among other styles of conflict management. Journal of Social Psychology, 129, 681-690.

Van de Vliert, E., Euwema, M.C. \& Huismans, S.E. (1995). Managing conflict with a subordinate and a supervisor: Effectiveness of conglomerated behavior. Journal of Applied Psychology, 80, 271-281.

Van Sell, M., Brief, A.P., \& Schuler, R.S. (1981). Role conflict and role ambiguity: Integration of the literature and directions 
for future research. Human Relations, 34, 43-71.

Vigil-King, D.C. (2000). Team conflict, integrative conflict-management strategies, and team effectiveness: A field study. Unpublished Doctoral Dissertation, University of Tennessee, Knoxville.

Wall, V.D., Jr. \& Galanes, G. (1986). The SYMLOG dimensions and small group conflict. Central States Speech Journal, 37, 61-78.

Webb, J. \& Dawson, P. (1991). Measure for measure: Strategic change in an electronics instruments corporation. Journal of Management Studies, 28, 191-206.

Weber, M. (1946). From Max Weber: Essays in sociology. In H. H. Gerth \& C. W. Mills (Eds.). New York: Oxford University Press.

Wilmot, W., \& Hocker, J. (2005). Interpersonal conflict. McGraw Hill.

\section{Notes}

Note 1. Model of Conflict Handling Style and Interactions

Note 2. The Styles of Handling Interpersonal Conflict

Note 3. Summary of Scales Items and Measure of Scale Reliabilities

Note 4. Pearson Correlations among Key Variables

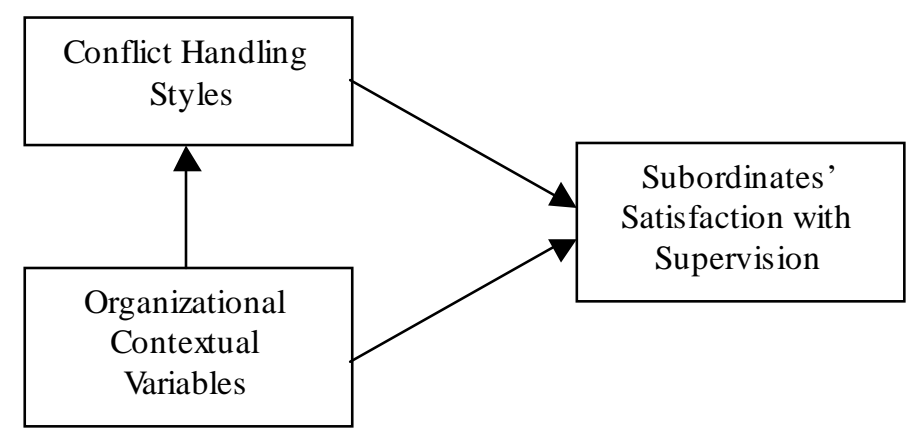

Figure 1. Model of Conflict Handling Style and Interactions

Conflict handling styles and its interactions variables involving organizational contextual variables i.e. span of control and structure; and subordinates' supervision with satisfaction.

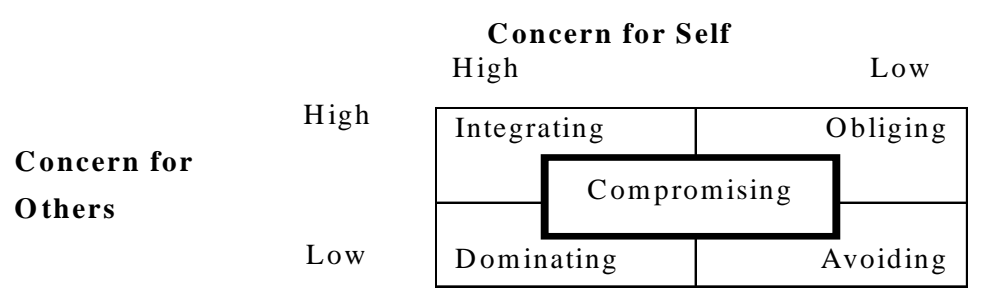

Figure 2. The Styles of Handling Interpersonal Conflict

(Adapted from Rahim and Bonoma, 1979)

The five conflict styles that emerge from various combinations of two dimension i.e. concern for self and concern for others. 
Table 1. Summary of Scales Items and Measure of Scale Reliabilities

\begin{tabular}{|c|c|}
\hline \multicolumn{1}{|c|}{ Scales } & Cronbach Alpha \\
\hline Conflict Handling Styles & .95 \\
\hline Integrating & .85 \\
\hline Obliging & .78 \\
\hline Compromising & .90 \\
\hline Dominating & .78 \\
\hline Avoiding & \\
\hline Organizational Contexts & .86 \\
\hline Structure & n.a. \\
\hline Span of control & .86 \\
\hline
\end{tabular}

n.a. Indicates alpha is not applicable

The internal consistency reliability coefficients for all the scales were satisfactory (Nunnally, 1978). All the scales had coefficient Cronbach Alpha greater than .78.

Table 2. Pearson Correlations among Key Variables

\begin{tabular}{|l|l|l|l|l|l|l|l|l|l|}
\hline & Variables & 1 & 2 & 3 & 4 & 5 & 6 & 7 & 8 \\
\hline 1 & $\begin{array}{l}\text { Superior Span } \\
\text { of Control }\end{array}$ & 1.000 & & & & & & & \\
\hline 2 & Integrating & -.134 & 1.000 & & & & & & \\
\hline 3 & Obliging & -.130 & $.493^{* *}$ & 1.000 & & & & & \\
\hline 4 & Avoiding & -.070 & -.203 & $.177^{*}$ & 1.000 & & & & \\
\hline 5 & Compromising & .048 & $.519^{* *}$ & $.352^{* *}$ & .004 & 1.000 & & & \\
\hline 6 & Dominating & .111 & $-.429 * *$ & $-.155^{\mathrm{n}}$ & $.327^{* *}$ & .015 & 1.000 & & \\
\hline 7 & Dominating & .032 & $.271^{* *}$ & .077 & $-.231^{* *}$ & .155 & $-.299 * *$ & 1.000 & \\
\hline 8 & Satisfaction & $-.142^{\mathrm{n}}$ & $.622^{* *}$ & $.289^{* *}$ & $-.238^{* *}$ & $.331^{* *}$ & $-.495^{* *}$ & $.193 *$ & 1.000 \\
& $\begin{array}{l}\text { with } \\
\text { supervision }\end{array}$ & & & & & & & & \\
\hline
\end{tabular}

* Correlation is significant at the .05 level ( 2 tailed)

** Correlation is significant at the .01 level ( 2 tailed)

$\mathrm{n} \quad$ correlation is marginally significant at .10

This table shows the intercorrelations among key variables such as conflict handling styles (i.e. integrating, obliging, avoiding, compromising and dominating), span of control, structure and satisfaction with supervision. 